\title{
3D printing of polybutadiene rubber cured by photo-induced thiol-ene chemistry: A proof of concept
}

\author{
M. Bragaglia*, F. R. Lamastra, V. Cherubini, F. Nanni \\ University of Rome 'Tor Vergata', Department of Enterprise Engineering 'Mario Lucertini', and INSTM RU Roma-Tor \\ Vergata, via del Politecnico 1, 00133 Rome, Italy
}

Received 1 August 2019; accepted in revised form 21 October 2019

\begin{abstract}
Mechanical performance of 3D printed 'Rubber-like' commercial resins are not comparable to typical vulcanized diene rubbers since they show lower strain at break. In the present work, samples made of liquid butadiene rubber have been photocured by thiol-ene chemistry and 3D printed. Morphological features and mechanical properties have been investigated by means of scanning electron microscopy (SEM), dynamic mechanical analysis (DMA) and tensile tests. The 3D printed samples show the characteristic mechanical properties of unfilled diene rubbers reaching a strain at break up to $400 \%$.
\end{abstract}

Keywords: rubber, $3 D$ printing, elastomers, additive manufacturing

\section{Introduction}

Additive manufacturing (AM) has found great attention in recent years as it allows the manufacturing of parts with complex shapes and geometries, which cannot be produced using the traditional subtractive manufacturing technologies [1]. Stereo-lithography (SLA) and digital light processing (DLP) are the most versatile liquid-based techniques, allowing the achievement of highest accuracy and precision [2]. Both these techniques are based on layer-by-layer localized UV photo-polymerization process of liquid resins with proprietary photoinitiators [3].

Although AM has been successfully applied to process many types of polymers, until now the 3D printing of diene rubbers has not been achieved. Thermoplastic elastomers and 'rubber-like' materials are available in form of filaments for fused deposition modeling as well as photo-curable resins suited for SLA and DLP. Although rubber-like materials with a range of hardness are commercially available [4], these materials don't show the typical behavior of vulcanized diene rubbers. The main drawbacks from the use of commercial resins are the lower values of elongation at break compared to diene-rubbers and the unfeasibility to modulate the elastic modulus values [5].

On the other hand, the development of suitable diene rubber formulations processable by SLA and DLP is very appealing, since elastomers and rubbers are widely used in several engineering applications, as automotive, aeronautical and aerospace vehicles, sports equipment and building materials due to their excellent mechanical properties such as elasticity and resilience, electrical and thermal insulation.

The development of 3D printable elastomers is quite challenging mainly because of the crosslinking process. SLA and DLP technologies involve the use of liquid precursor presenting an upper limit to viscosity. On the other hand, in order to obtain the high elasticity after crosslink, high molecular weight linear precursors are needed which typically traduces in highly viscous liquid or solid elastomers $[6,7]$. Among the possible crosslinking processes UV induced thiol-ene photopolymerization has proved to 
be a successfully way to photo-crosslink natural and synthetic rubber both in latex and in solid film state [8-10]. The thiol-ene photopolymerization proceeds by a free-radical step-growth polymerization manner [11]. The photolysis of the photo-initiator induces the hydrogen atom extraction from thiol group producing a thiyl radical (Initiation). The resulting thiyl radical reacts with the double bond of the unsaturated monomer and gives rise to a secondary free radical (propagation A). The latter extracts the hydrogen atom from a second thiol molecule producing a new thiyl radical (propagation B). The reaction terminates when two radical species couple $[12,13]$. The main advantages of using UV induced thiol-ene photopolymerization are the rapidity of the curing process, the use of solvent-free formulations and the low energy consumption, and also the possibility to photo-cure the polymer without the use of photoinitiator [14, 15], hence, it seems the most promising way for UV based 3D printing.

Up to now, the thiol-ene chemistry approach resulted effective to vulcanize diene-rubbers both in latex and in solid film state whereas, however, there are few researches investigating the photo-crosslink of rubbers. Very recent efforts in 3D printing of hydrocarbon elastomers have been proposed by Scott et al. [16] as well as UV-induced crosslinking of liquid silicone rubber to tune the 3D printed part mechanical properties [17, 18]. Moreover, Patel et al. [5] developed resin formulations based on epoxy aliphatic acrylate and aliphatic urethane diacrylate diluted with isobornyl acrylate to obtain highly stretchable and UV curable elastomers for DLP.

In this work, a liquid diene rubber (polybutadiene) has been photo-vulcanized using thiol-ene chemistry. 3D printed samples have been manufactured proving the 3D printing feasibility. The crosslinking reaction was studied by infrared spectroscopy and swelling test. 3D printed samples have also been characterized from a mechanical and morphological point of view by tensile test and electron microscopy.

\section{Materials and methods}

\subsection{Sample preparation}

Liquid polybutadiene (composition: $80 \%$ cis- and trans-1,4 and 20\% vinyl, $M_{\mathrm{w}} 5000$, Sigma Aldrich) was mechanically mixed with 1 parts per hundred rubber [phr] of photoinitiator ethyl(2,4,6-trimethylbenzoyl)-phenyl phosphinate (OMNIRAD TPO-L,
$M_{\mathrm{w}} 316,4 \mathrm{~g} / \mathrm{mol}$, IGM Resins). Then, the trimethylolpropanetris (3-mercaptopropionate) (assay $\geq 95 \%$, Sigma Aldrich) was added at three different concentrations (1, 2 and $5 \mathrm{phr}$ ) as crosslinking agent. The compounds were homogenized by mechanical mixing using a planetary mixer (Thinky ARE 250) at $900 \mathrm{rpm}$ for 2 minutes. The material was poured in a Teflon mold $\left(12 \times 50 \times 3 \mathrm{~mm}^{3}\right)$ and cured at a radiant power of $1.25 \mathrm{~mW} / \mathrm{cm}^{2}$ for 20 minutes by a UV lamp (40 W, spectral emission range of 320-410 nm and maximum peak at $351 \mathrm{~nm}$, Waldman) at room temperature $(R T)$.

The most effective curing agent formulation was selected to manufacture, as 3D proof of concept, a UVcured stacked layer sample as follows: (i) $5 \mathrm{~mL}$ of polybutadiene containing the photoinitiator (1 phr) and the crosslinker ( $5 \mathrm{phr}$ ) were dosed by a syringe pump system (Figure 1b) and deposited on an Y-motorized aluminum building plate by an $\mathrm{X}-\mathrm{Z}$ axis motorized deposition head system (Figure 1a).

(ii) The deposited material was flattened to the desired thickness $(\cong 100 \mu \mathrm{m})$ by a stainless steel blade moving at $10 \mathrm{~mm} / \mathrm{s}$ and partially UV cured in a second run by a UV lamp (maximum peak at $366 \mathrm{~nm}$, $10 \mathrm{~W}$, Merck MGaA) at $1 \mathrm{~mm} / \mathrm{s}$. Both the blade and UV lamp are integral with the deposition head system as displayed in Figure 1c. (iii) The deposition head lifted up by $100 \mu \mathrm{m}$ and the previous steps have been repeated to reach seven layers. A post curing process consisting of exposure to radiant power of $1.25 \mathrm{~mW} / \mathrm{cm}^{2}$ for 20 minutes by a UV lamp (spectral emission range of 320-410 nm and maximum peak at $351 \mathrm{~nm}, 40 \mathrm{~W}$, Waldman) at room temperature $(R T)$ has been performed on the printed sample to ensure the complete crosslinking.

\subsection{Characterization methods}

The viscosity at 25,35 and $50^{\circ} \mathrm{C}$ of liquid polybutadiene was measured by means of a Kinexus Lab+ rheometer (Malvern), using a frequency sweep configuration $(0.01-10 \mathrm{~Hz})$, according to ASTM D2501 to check its processability with SLA and/or DLP 3D printers. Commercial Formlabs clear ${ }^{\mathrm{TM}}$ resin was also tested as reference.

Fourier transform infrared (FT-IR) analysis (Perkin Elmer, Spectrum 100) was performed on samples containing $5 \mathrm{phr}$ of crosslinking agent before and after the curing process to assess the state of crosslinking. The samples containing 1 and $2 \mathrm{phr}$ of the 


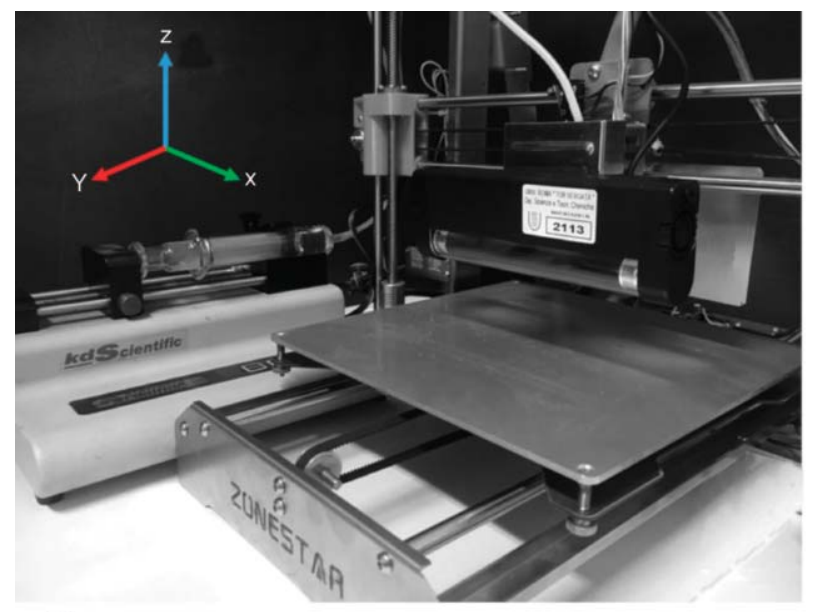

a)

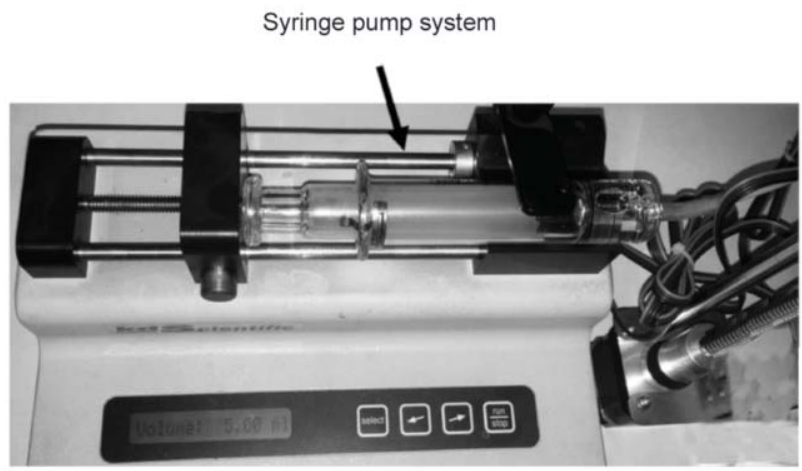

b)

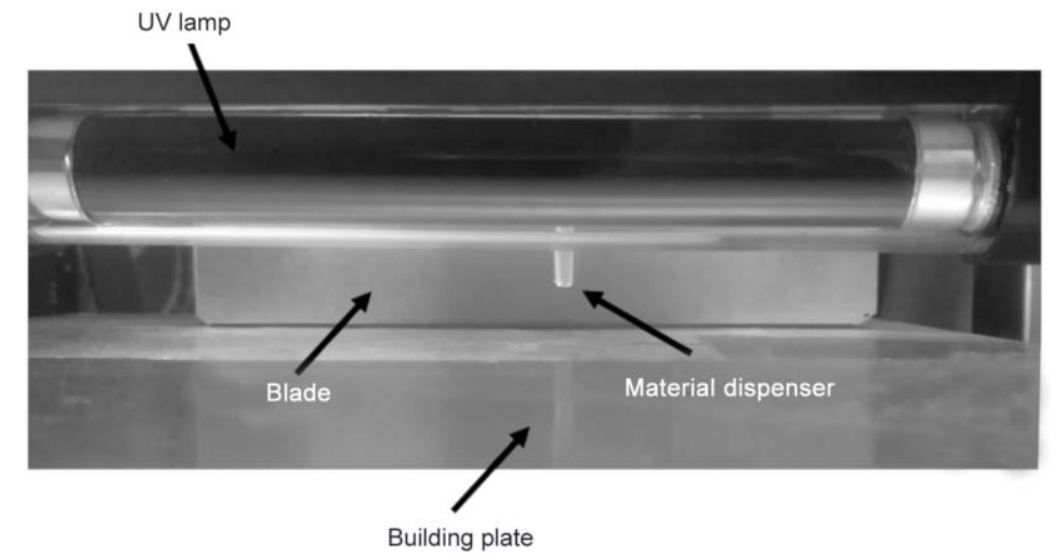

Figure 1. 3D printing system. Overall view (a), syringe pump system (b) and UV curing system (c).

crosslinking agent remained gel-like also after the photo-vulcanization therefore these samples were not be characterized. Spectra were acquired in the range $4000-400 \mathrm{~cm}^{-1}, 32$ scans were performed for each sample at a resolution of $4 \mathrm{~cm}^{-1}$. Then, the intensities $(I)$ of the peaks associated to the stretching modes of $\mathrm{C}=\mathrm{C}$ double bonds involved in the crosslinking (at $1656 \mathrm{~cm}^{-1}$ ) and to $\mathrm{CH}_{2}$ bonds that do not participate to the cure process (at $2910 \mathrm{~cm}^{-1}$ ) were measured from the spectra of uncured and cured samples (Figure 1a). The crosslink effectiveness was evaluated from the value of ratio

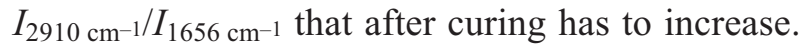
Crosslink density of UV cured samples have been measured by solvent swelling test according to ASTM D6814-02e1. Sample was allowed to swell in Tetrahydrofuran (THF) solvent (assay $>99.9 \%$ Sigma Aldrich) for 24 hours at $R T$. The volume fraction of the swollen rubber $\left(V_{\mathrm{r}}\right)$ was calculated by Equation (1): where: $m_{1}$ and $\rho_{1}$ are the weight and the density of dry sample evaluated following ASTMD792 by pycnometer (Sartorius); $m_{2}$ and $\rho_{2}$ are the weight of solvent in the swollen sample (calculated as $m_{3}-m_{1}$ where $m_{3}$ is the weight of swollen gel sample measured immediately after immersion) and the solvent density, respectively.

Morphology of the 3D printed samples, realized with the layer-by-layer approach, were investigated by scanning electron microscopy (FEG-SEM Leo supra 35, Zeiss). Mechanical properties of the samples

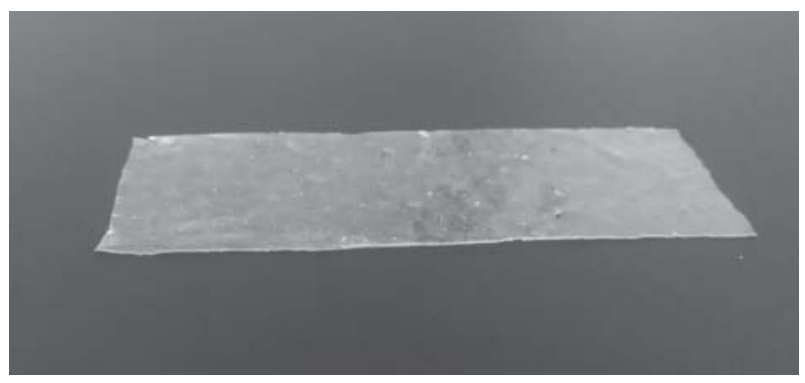

Figure 2. 3D printed tensile test specimen.

$V_{\mathrm{r}}=\frac{\text { Volume of rubber }}{\text { Volume of rubber }+ \text { Volume of solvent }}=\frac{\frac{m_{1}}{\rho_{1}}}{\frac{m_{1}}{\rho_{1}}+\frac{m_{2}}{\rho_{2}}}$ 


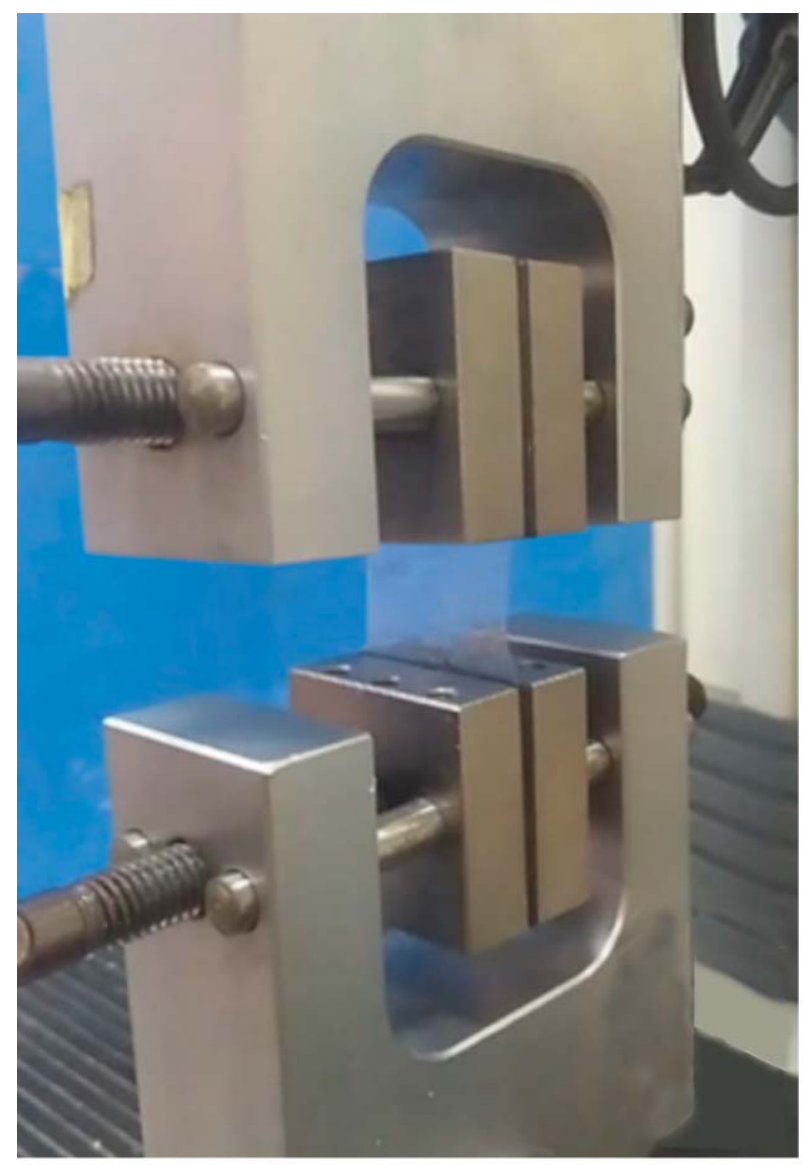

a)

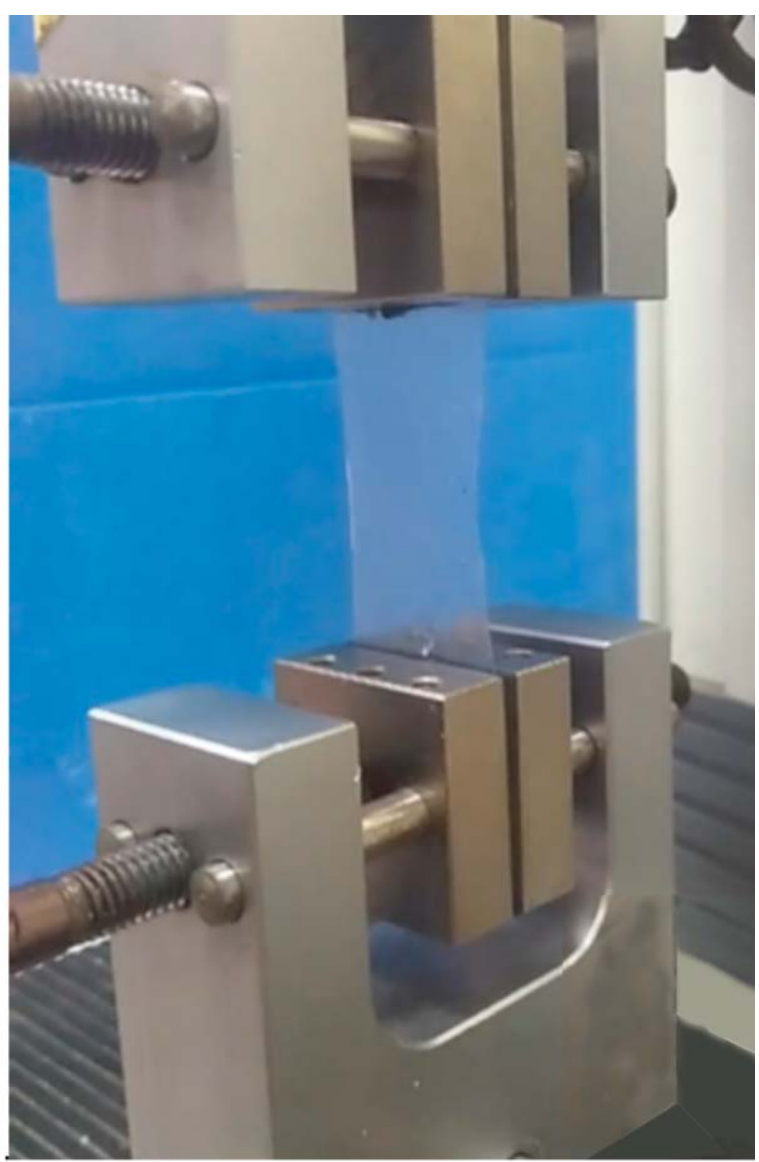

b)

Figure 3. 3D printed sample showing high elongation before (a) and after (b) load application.

were assessed by dynamic mechanical analysis (DMA, Tritec 2000 DMA, Triton Technology). Samples, having dimension $10 \times 4 \times 0.56 \mathrm{~mm}$, have been tested in tensile configuration at constant frequency $1 \mathrm{~Hz}$ and displacement $0.05 \mathrm{~mm}$ in the temperature range -110 to $50^{\circ} \mathrm{C}$. Tensile tests were carried out on rectangular specimens (Figure 2) cut out from the UV-cured 3D printed samples having dimension $80 \times 25 \times 0.56 \mathrm{~mm}$.

Uniaxial tensile tests (universal testing machine Lloyd LRX, $50 \mathrm{~N}$ load cell, crosshead speed of $500 \mathrm{~mm} / \mathrm{min}$ (Figure 3)) have been performed according to ASTM D412.

\section{Results and discussion}

Viscosity values at 25,35 and $50^{\circ} \mathrm{C}$ of liquid polybutadiene are $4.71 \pm 0.02,2.89 \pm 0.03$ and $1.50 \pm 0.03 \mathrm{~Pa} \cdot \mathrm{s}$, respectively and are similar to those of commercial resins used in stereo-lithographic $3 \mathrm{D}$ printers whose values range from 0.25 to $5 \mathrm{~Pa} \cdot \mathrm{s}$ [19]. In particular, the tested commercial Formlabs ${ }^{\mathrm{TM}}$ clear resin has viscosity value of $1.45 \mathrm{~Pa} \cdot \mathrm{s}$ at $35^{\circ} \mathrm{C}$, which is comparable to the viscosity of polybutadiene formulation tested at $50^{\circ} \mathrm{C}$, meaning that the rheological behavior during $3 \mathrm{D}$ printing is very similar and the polybutadiene formulation can be successfully processed via SLA 3D process.

The FT-IR analysis performed on uncured samples, displayed in Figure 4a, showed the typical absorption bands of polybutadiene cis- and trans-1,4. In particular, the bands at 3070 and $3050 \mathrm{~cm}^{-1}$ correspond to $\mathrm{CH}$ stretching vibrations. A strong absorption around $1656 \mathrm{~cm}^{-1}$ corresponding to $\mathrm{C}=\mathrm{C}$ stretching vibrations, and peaks at 967 and $740 \mathrm{~cm}^{-1}$, associated to wagging of $\mathrm{CH}$, are characteristic of trans1,4 and cis-1,4 units respectively, moreover, peak at $910 \mathrm{~cm}^{-1}$, attributed to wagging of $\mathrm{CH}_{2}$ of cis-1,2 units $[20,21]$.

The FT-IR analysis on photo-cured samples shows a variation of intensity of characteristic peaks due to crosslinking. Moreover, the presence of a peak at around $3400 \mathrm{~cm}^{-1}$ corresponding to $\mathrm{OH}$ stretching vibration ascribable to moisture is recorded. FT-IR analysis revealed a higher value of $I_{2910 \mathrm{~cm}^{-1}} / I_{1656 \mathrm{~cm}^{-1}}$ for the cured sample (3.1) with respect to the uncured one (1.5) suggesting the reaching of crosslinking. Moreover, the disappearance after curing of the peak in the range $2625-2525 \mathrm{~cm}^{-1}$ corresponding to 

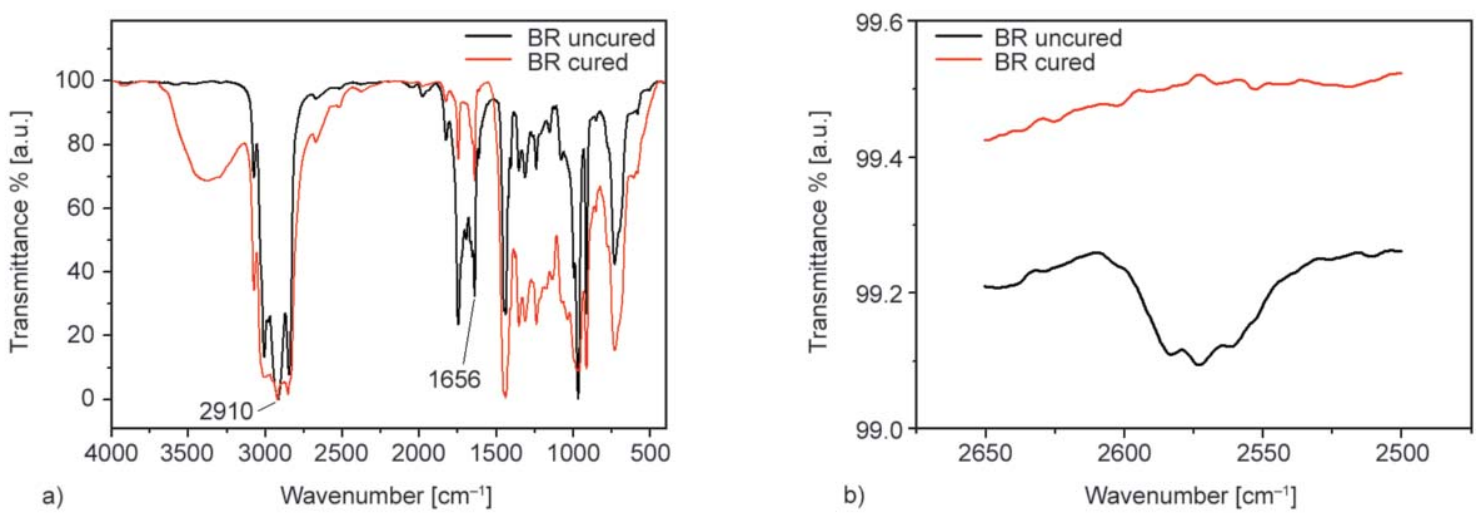

Figure 4. (a) Normalized FTIR spectra of the uncured and cured liquid polybutadiene (b) detail of S-H stretching peak.

S-H stretching of the trimethylolpropanetris(3-mercaptopropionate) suggests that all crosslinking agent added to the liquid rubber reacted during photo-vulcanization (Figure 4b) [11].

The swelling test confirmed the reaching of high crosslinking degree. In fact, the volume fraction of swollen rubber is $26 \%$. The degree of swelling (amount of solvent imbibed) depends on the crosslink density. In particular, the lower the swollen volume fraction, the higher the crosslink density [22, 23]. Anyway, it has to be highlighted that even if swelling test is a simple and very popular experiment to determine the cross-link density, more than once the results suffer from high uncertainty. In particular, the difficulty in the correct determination of the volumetric fraction of rubber in the swollen state, as well as the presence of insoluble ingredients that may alter the 'real' rubber density, may affect the results [24]. SEM micrographs of the cross section of the 3D printed sample show the structure consisting of seven adjacent $80 \mu \mathrm{m}$ thick layers (Figure 5a) showing good adhesion (Figure 5b).
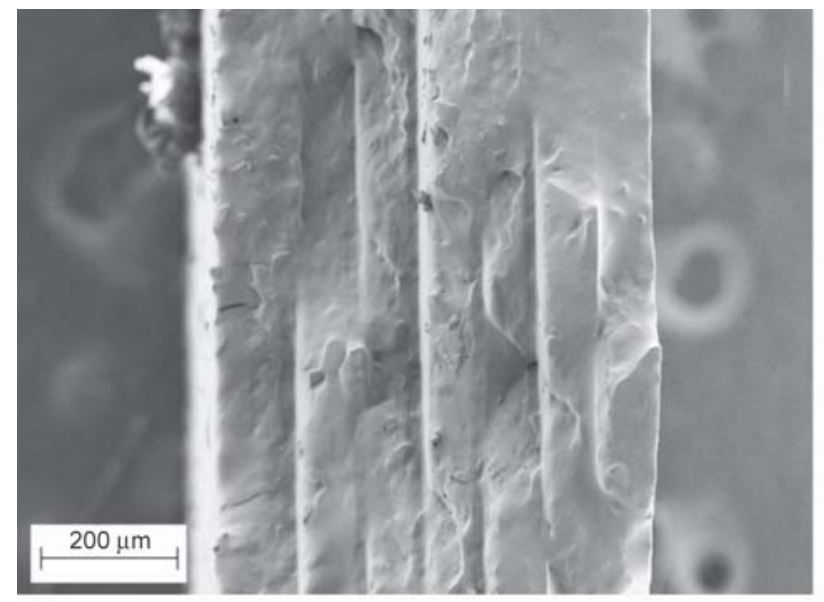

a)
Adhesion between layers is fundamental in order to achieve good mechanical performances of the 3D printed parts [25]. The variation of storage modulus with temperature $\left(2 \cdot 10^{9}-2 \cdot 10^{6} \mathrm{MPa}\right)$ and the glass transition temperature $\left(T_{\mathrm{g}}-77.5^{\circ} \mathrm{C}\right)$ taken as the maximum of $\tan \delta$ peak (Figure $6 \mathrm{a}$ ) are characteristic of vulcanized polybutadiene rubber compound and therefore confirm that the selected curing agents formulation is effective [26]. A typical stress-strain curve of the sample is reported in Figure 6b showing the characteristic behavior and tensile strength of unfilled diene rubbers $[27,28]$. The tensile modulus at $100 \%$ strain, the stress at break and the strain at break, obtained from the acquired stress-strain curves, are $0.3 \pm 0.02,0.54 \pm 0.04 \mathrm{MPa}$, and $402 \pm 10 \%$ respectively. The obtained value for strain at break ( $\approx 400 \%$ ) has to be highlighted, being far higher than commercially available UV curable rubber-like resins for SLA and DLP, for which the highest elongation is about $170-220 \%$ [5].

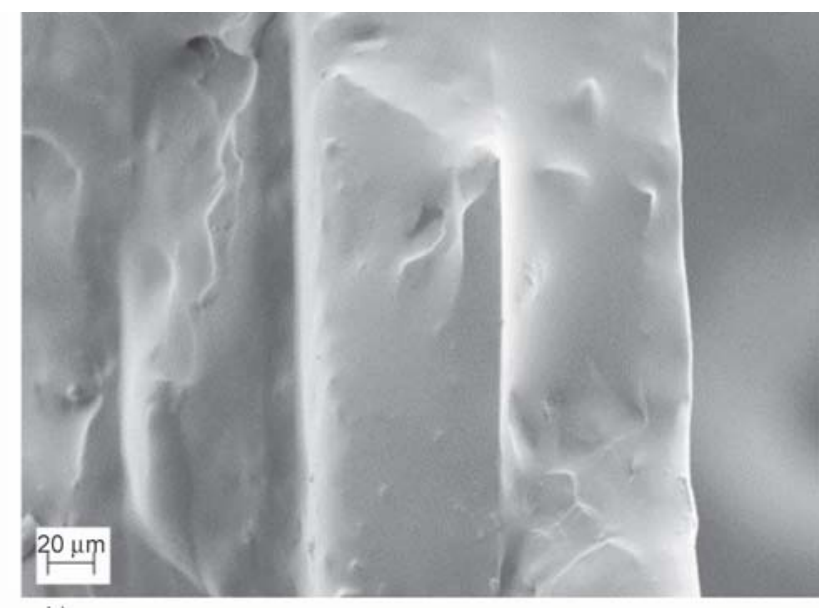

b)

Figure 5. SEM images of the cross section of UV-cured layer-by-layer sample (a) highlight of two layers (b). 

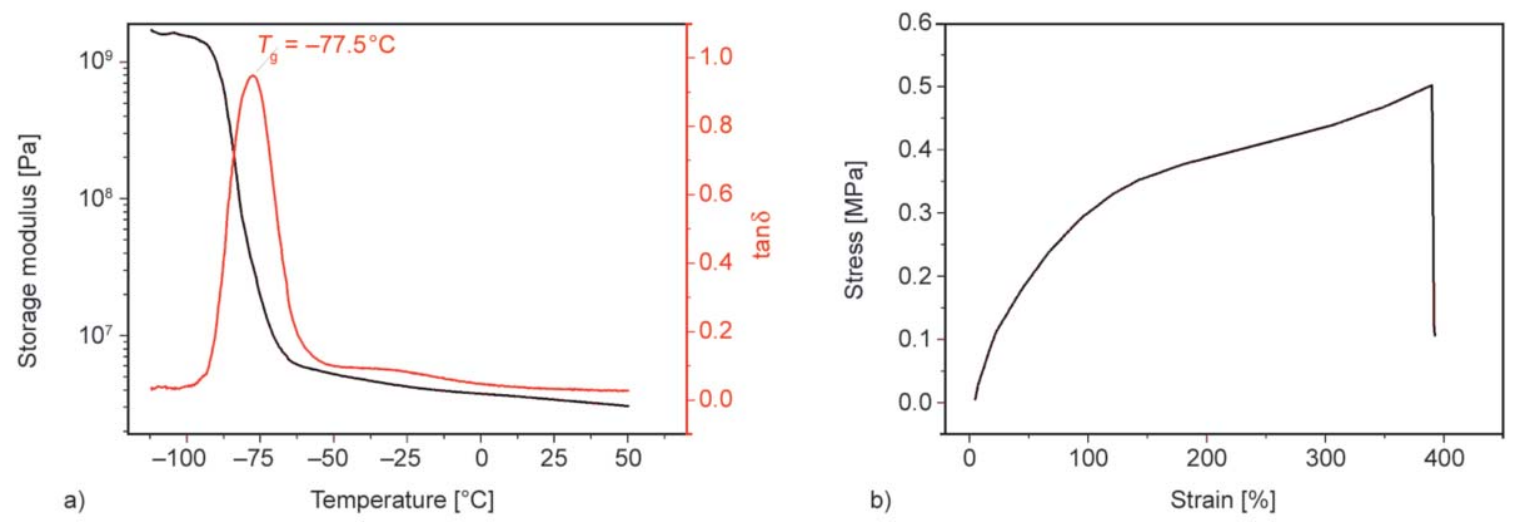

Figure 6. DMA curves (a) and typical stress-strain curve (b) of UV-cured layer-by-layer sample.

\section{Conclusions}

In this work, the thiol-ene chemistry was successfully applied to photo-crosslink a liquid butadiene rubber. The feasibility of 3D printing of the investigated liquid rubber formulation was confirmed by the manufacturing of $3 \mathrm{D}$ printed samples. 3D printed BR specimens show a good adhesion between adjacent layers leading to good mechanical properties comparable to vulcanized diene rubbers. The obtained elongation at break (400\%) are far higher than commercial available 'rubber-like' resins.

\section{Acknowledgements}

Authors wish to thank Giulia Cappucci and Lorenzo Paleari for their support during the experimental campaign.

\section{References}

[1] Tofail S. A. M., Koumoulos E. P., Bandyopadhyay A., Bose S., Donoghue L. O., Charitidis C.: Additive manufacturing: Scientific and technological challenges, market uptake and opportunities. Materials Today, 21, 22-37 (2018).

https://doi.org/10.1016/j.mattod.2017.07.001

[2] Ligon S. C., Liska R., Stampfl J., Gurr M., Muilhaupt R.: Polymers for $3 \mathrm{D}$ printing and customized additive manufacturing. Chemical Reviews, 117, 10212-10290 (2017). https://doi.org/10.1021/acs.chemrev.7b00074

[3] Gross B. C., Erkal J. L., Lockwood S. Y., Chen C., Spence D. M.: Evaluation of 3D printing and its potential impact on biotechnology and the chemical sciences. American Chemical Society, 86, 3240-3253 (2014). https://doi.org/10.1021/ac403397r

[4] Lukić M., Clarke J., Tuck C., Whittow W., Wells G.: Printability of elastomer latex for additive manufacturing or 3D printing. Journal of Applied Polymer Science, 133, 42931/1-42931/27 (2016). https://doi.org/10.1002/app.42931
[5] Patel D. K., Sakhaei A. H., Layani M., Zhang B., Ge Q., Magdassi S.: Highly stretchable and UV curable elastomers for digital light processing based 3D printing. Advanced Materials, 29, 1606000/1-1606000/7 (2017). https://doi.org/10.1002/adma.201606000

[6] Kuttner C., Tebbe M., Schlaad H., Burgert I., Fery A.: Photochemical synthesis of polymeric fiber coatings and their embedding in matrix material: Morphology and nanomechanical properties at the fiber-matrix interface. Applied Materials and Interfaces, 4, 3484-3492 (2012).

https://doi.org/10.1021/am300576c

[7] Mendes-Felipe C., Oliveira J., Etxebarria I., Vilas-Vilela J. L., Lanceros-Mendez S.: State-of-the-art and future challenges of UV curable polymer-based smart materials for printing technologies. Advanced Materials Technologies, 4, 1800618/1-1800618/16 (2019). https://doi.org/10.1002/admt.201800618

[8] Schlögl S., Trutschel M-L., Chassé W., Letofsky-Papst I., Schaller R., Holzner A., Riess G., Kern W., Saalwächter K.: Photo-vulcanization using thiol-ene chemistry: Film formation, morphology and network characteristics of UV crosslinked rubber latices. Polymer (United Kingdom), 55, 5584-5595 (2014). https://doi.org/10.1016/j.polymer.2014.06.007

[9] Choi S-S., Hong J-P., Seo Y. S., Chung S. M., Nah C.: Fabrication and characterization of electrospun polybutadiene fibers crosslinked by UV irradiation. Journal of Applied Polymer Science, 101, 2333-2337 (2005). https://doi.org/10.1002/app.23764

[10] Lenko D., Schlögl S., Temel A., Schaller R., Holzner A., Kern W.: Dual crosslinking of carboxylated nitrile butadiene rubber latex employing the thiol-ene photoreaction. Journal of Applied Chemistry, 129, 2735-2743 (2013). https://doi.org/10.1002/app.38983

[11] Wutticharoenwong K., Soucek M. D.: Influence of the thiol structure on the kinetics of thiol-ene photopolymerization with time-resolved infrared spectroscopy. Macromolecular Materials and Engineering, 293, 4556 (2008). https://doi.org/10.1002/mame.200700175 
[12] Xue L., Zhang Y., Zuo Y., Diao S., Zhang J., Feng S.: Preparation and characterization of novel UV-curing silicone rubber via thiol-ene reaction. Materials Letters, 106, 425-427 (2013).

https://doi.org/10.1016/j.matlet.2013.05.084

[13] Kuttner C., Hanisch A., Schmalz H., Eder M., Schlaad H., Burgert I., Fery A.: Influence of the polymeric interphase design on the interfacial properties of (fiberreinforced) composites. Applied Materials and Interfaces, 5, 2469-2478 (2013).

https://doi.org/10.1021/am302694h

[14] Decker C., Nguyen Thi Viet T.: Photocrosslinking of functionalized rubbers IX. Thiol-ene polymerization of styrene-butadiene-block-copolymers. Polymer, 41, 39053912 (2000).

https://doi.org/10.1016/S0032-3861(99)00649-7

[15] Kuttner C., Maier P. C., Kunert C., Schlaad H., Fery A.: Direct thiol-ene photocoating of polyorganosiloxane microparticles. Langmuir, 29, 16119-16126 (2013). https://doi.org/10.1021/la4039864

[16] Scott P. J., Meenakshisundaram V., Chartrain N. A., Sirrine J. M., Williams C. B., Long T. E.: Additive manufacturing of hydrocarbon elastomers via simultaneous chain extension and cross-linking of hydrogenated polybutadiene. ACS Applied Polymer Materials, 1, 684-690 (2019).

https://doi.org/10.1021/acsapm.8b00150

[17] Zhao T., Yu R., Li S., Li X., Zhang Y., Yang X., Zhao X., Wang C., Liu Z., Dou R., Huang W.: Superstretchable and processable silicone elastomers by digital light processing 3D printing. Applied Materials and Interfaces, 11, 14391-14398 (2019).

https://doi.org/10.1021/acsami.9b03156

[18] Huang P., Xia Z., Cui S.: 3D printing of carbon fiberfilled conductive silicon rubber. Materials and Design, 142, 11-21 (2018).

https://doi.org/10.1016/j.matdes.2017.12.051

[19] Hinczewski C., Corbel S., Chartier T.: Ceramic suspensions suitable for stereolithography. Journal of the European Ceramic Society, 18, 583-590 (2002). https://doi.org/10.1016/S0955-2219(97)00186-6

[20] Prokof'eva N. I., Shvartsberg S., Sperantova I. B.: Calculation of the infrared spectrum of 1,4-trans-polybutadiene. Journal of Applied Spectroscopy, 27, 1185 1188 (1977).

https://doi.org/10.1007/BF00625908
[21] Zeng X-R., Ko T-M.: Thermal crosslinking of cis-1,4polybutadiene at ultrahigh pressures. Applied Polymer Science, 67, 2131-2140 (1996).

https://doi.org/10.1002/(SICI)10974628(19980328)67:13<2131::AID-APP3>3.0.CO;2-F

[22] Barikani M., Hepburn C.: Determination of crosslink density by swelling in the castable polyurethane elastomer based on 1/4-cyclohexane diisocyanate and paraphenylene diisocyanate. Iranian Journal of Polymer Science and Technology, 1, 1-5 (1992).

[23] Mckenna G. B., Flynn K. M., Chen Y.: Swelling in crosslinked natural rubber: Experimental evidence of the crosslink density dependence of $\chi$. Polymer, 31, 1937-1945 (1990). https://doi.org/10.1016/0032-3861(90)90020-Y

[24] Valentín J. L., Carretero-González J., Mora-Barrantes I., Chassé W., Saalwächter K.: Uncertainties in the determination of cross-link density by equilibrium swelling experiments in natural rubber. Macromolecules, 41, 4717-4729 (2008). https://doi.org/10.1021/ma8005087

[25] Ngo T. D., Kashani A., Imbalzano G., Nguyen K. T. Q., Hui D.: Additive manufacturing (3D printing): A review of materials, methods, applications and challenges. Composites Part B: Engineering, 143, 172-196 (2018). https://doi.org/10.1016/j.compositesb.2018.02.012

[26] Robertson C. G., Lin C. J., Rackaitis M., Roland C. M.: Influence of particle size and polymer-filler coupling on viscoelastic glass transition of particle-reinforced polymers. Macromolecules, 41, 2727-2731 (2008). https://doi.org/10.1021/ma7022364

[27] Oh J. S., Isayev A. I.: Continuous ultrasonic devulcanization of unfilled butadiene rubber. Journal of Applied Polymer Science, 93, 1166-1174 (2004). https://doi.org/10.1002/app.20508

[28] Oh J. S., Ghose S., Isayev A. I.: Effects of ultrasonic treatment on unfilled butadiene rubber. Journal of Polymer Science Part B: Polymer Physics, 41, 2959-2968 (2003).

https://doi.org/10.1002/polb.10606 